Review

\title{
Flaviviral Replication Complex: Coordination between RNA Synthesis and 5'-RNA Capping
}

\author{
Valerie J. Klema ${ }^{1}$, Radhakrishnan Padmanabhan ${ }^{2}$ and Kyung H. Choi ${ }^{1, *}$ \\ ${ }^{1}$ Department of Biochemistry and Molecular Biology, Sealy Center for Structural Biology and \\ Molecular Biophysics, University of Texas Medical Branch at Galveston, Galveston, TX 77555-0647, \\ USA; E-Mail: vaklema@utmb.edu \\ 2 Department of Microbiology and Immunology, Georgetown University School of Medicine, \\ Washington, DC 20057, USA; E-Mail: rp55@georgetown.edu \\ * Author to whom correspondence should be addressed; E-Mail: kychoi@utmb.edu; \\ Tel.: +1-409-747-1402; Fax: +1-409-747-1404.
}

Academic Editor: David D. Boehr

Received: 30 June 2015 / Accepted: 4 August 2015 / Published: 13 August 2015

\begin{abstract}
Genome replication in flavivirus requires (-) strand RNA synthesis, (+) strand RNA synthesis, and 5'-RNA capping and methylation. To carry out viral genome replication, flavivirus assembles a replication complex, consisting of both viral and host proteins, on the cytoplasmic side of the endoplasmic reticulum (ER) membrane. Two major components of the replication complex are the viral non-structural (NS) proteins NS3 and NS5. Together they possess all the enzymatic activities required for genome replication, yet how these activities are coordinated during genome replication is not clear. We provide an overview of the flaviviral genome replication process, the membrane-bound replication complex, and recent crystal structures of full-length NS5. We propose a model of how NS3 and NS5 coordinate their activities in the individual steps of (-) RNA synthesis, $(+)$ RNA synthesis, and $5^{\prime}$-RNA capping and methylation.
\end{abstract}

Keywords: viral replication complex; flavivirus; RNA-dependent RNA polymerase; RNA synthesis; 5'-RNA capping; NS5; NS3 


\section{Flavivirus Genome and Viral Non-Structural (NS) Proteins}

Flaviviruses are positive (+) sense RNA viruses belonging to the family Flaviviridae, which also includes Hepacivirus and Pestivirus. The Flavivirus genus includes over 70 viruses, many of which cause arboviral diseases in humans, such as dengue (DENV), West Nile (WNV), tick-borne encephalitis (TBEV), and yellow fever virus. The $11 \mathrm{~kb}$ flaviviral RNA genome consists of a $5^{\prime}$-cap, a $5^{\prime}$-untranslated region (5'-UTR), a single open reading frame (ORF), and a $3^{\prime}$-UTR. The $5^{\prime}$ - and $3^{\prime}$-UTRs contain conserved RNA secondary structures that are important for viral replication, including sequences that mediate long range $5^{\prime}$ - and $3^{\prime}$-RNA interactions [1-8]. The viral ORF is translated into a polyprotein, C-prM-E-NS1-NS2A-NS2B-NS3-NS4A-NS4B-NS5, that is subsequently cleaved into individual proteins by viral and host proteases. Three structural proteins (C, prM, and E) form capsids and seven non-structural (NS) proteins (NS1, NS2A, NS2B, NS3, NS4A, NS4B, NS5) are involved in the assembly of the viral replication complex [9]. Among NS proteins, the functions of NS3 and NS5 in viral replication are well established. NS3 consists of an N-terminal serine protease and a C-terminal helicase. NS3 protease activity requires NS2B as a cofactor, and cleaves the viral polyprotein at several positions between NS proteins [10-14]. The NS3 helicase domain has helicase, RNA-stimulated nucleoside triphosphate hydrolase and 5'-RNA triphosphatase activities [15-19]. Helicase activity would be required for unwinding the double-stranded (ds) RNA intermediate formed during genome synthesis, and 5'-RNA triphosphatase activity is required for 5'-RNA cap formation [20,21]. NS5, the largest viral protein $(103 \mathrm{kDa})$, consists of an $\mathrm{N}$-terminal methyltransferase (MTase) and a C-terminal RNA-dependent RNA polymerase (RdRp). The RdRp is involved in viral genome replication and carries out both (-) and (+) strand RNA synthesis [22]. The NS5 MTase has RNA guanylyltransferase and methyltransferase activities necessary for 5'-RNA capping and cap methylations [23,24]. Little is known about functions of the membrane proteins NS2A, NS4A, and NS4B, but they are likely involved in membrane alterations and assembly of the viral replication complex on the cellular membrane [25-29]. NS1 may be involved in multiple steps in the viral life cycle, including viral replication [30-33]. NS1 exists as two forms, either a membrane-bound dimer in the viral replication complex or a secreted hexameric form with as-yet-unknown function [34,35]. More extensive reviews of NS protein functions can be found elsewhere [36,37].

\section{Flavivirus Genome Replication}

The flavivirus replication complex carries out RNA synthesis, RNA capping and RNA methylation steps to produce the genome with a type 1 cap structure $\left({ }^{\mathrm{m} 7} \mathrm{GpppN}{ }^{\mathrm{m}}-\mathrm{RNA}\right)$ at its $5^{\prime}$ end. RNA synthesis in flavivirus is semi-conservative and asymmetric. The (+) sense RNA, which is the same polarity as the viral genome, is predominantly formed over the (-) sense RNA; single-stranded (ss) RNA found in flavivirus-infected cells is (+) sense RNA, and (-) strand RNA is only detected in the dsRNA form [38]. When DENV or Kunjin virus-infected cells were incubated with a radiolabeled NTP $\left({ }^{3} \mathrm{H}-\mathrm{UTP}\right.$ or ${ }^{32} \mathrm{P}$-labeled guanosine-5'-triphosphate (GTP)), three radiolabeled RNA products were identified: a double-stranded replicative form (RF) RNA, single-stranded genome length RNA, and the slowest migrating, replicative intermediate (RI) $[22,39,40]$. RNase treatment of the RI suggested that the RI likely contains growing nascent RNAs on the RF template, which displace a pre-existing strand of the 
same polarity (Figure 1A). One to ten nascent RNA strands are synthesized on one RF template at a time [29,39]. Based on these observations, a general scheme of RNA synthesis and the associated required enzymatic activities are outlined in Figure 1A. The genomic (+) sense RNA is first used as a template by NS5 RdRp to synthesize a complementary (-) sense RNA. The (-) strand RNA remains base-paired with the $(+)$ strand RNA, resulting in a dsRNA intermediate. The $(-)$ strand within the dsRNA intermediate then serves as the template to generate (+) sense RNA. NS3 helicase activity may be required to unwind the dsRNA. The nascent $(+)$ strand synthesized on the (-) RNA template displaces a pre-existing $(+)$ strand and is released as a dsRNA product. The newly generated dsRNA is then recycled as a template to generate additional copies of $(+)$ sense RNA.
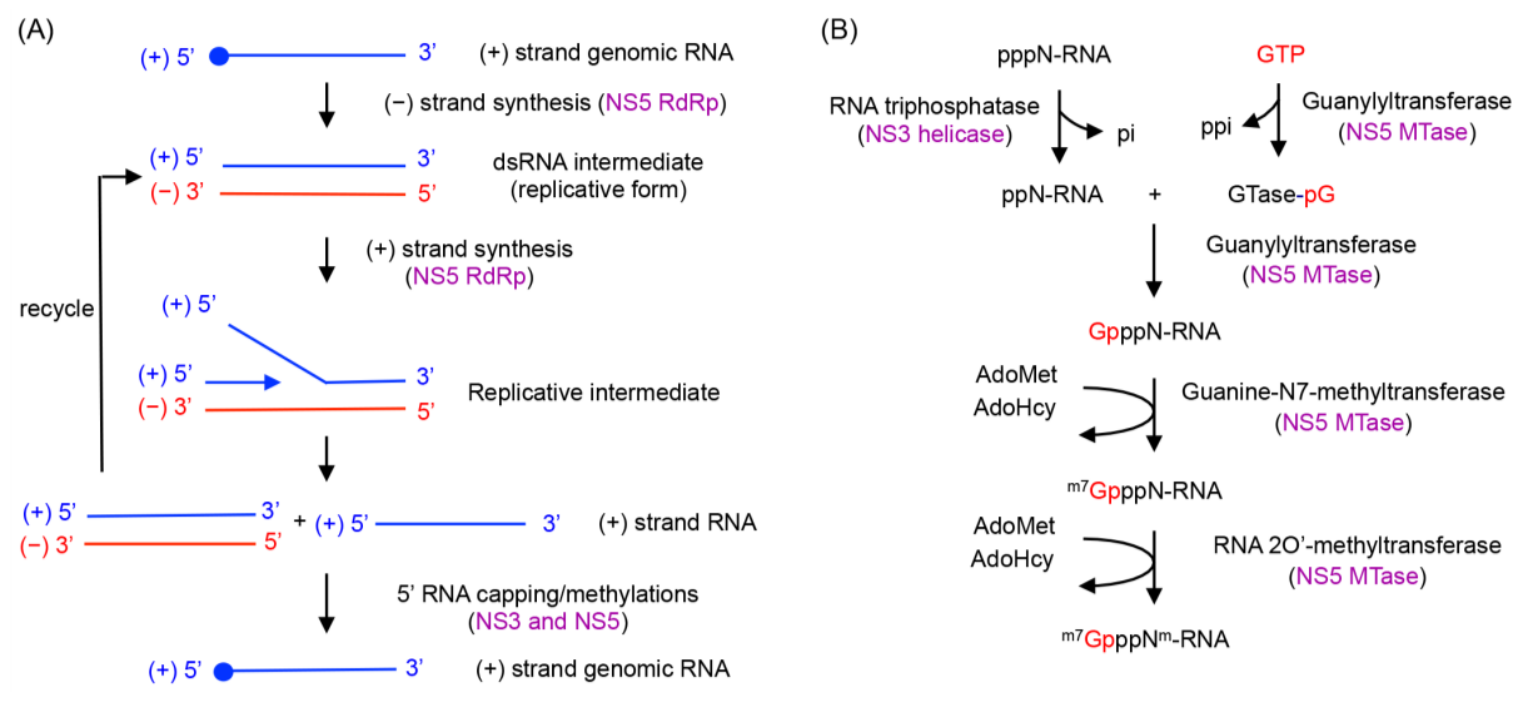

Figure 1. RNA synthesis by the flavivirus replication complex. (A) RNA replication by flaviviral NS3 and NS5 proteins. A (+) strand genomic RNA serves as a template to produce (-) strand RNA. The (-) strand RNA exists as a dsRNA intermediate (replicative form). The $(-)$ strand within the dsRNA intermediate is then used as a template for $(+)$ strand RNA synthesis. The dsRNA product is released and recycled for additional (+) strand synthesis. Flavivirus replication is asymmetric, and multiple copies of $(+)$ strand RNA are synthesized from a (-) strand template. The (+) strand RNA is then capped and methylated by NS3 and NS5 to form (+) strand genomic RNA. The identities of the enzymes involved in each step are shown in purple. (B) $5^{\prime}$-RNA cap synthesis by flaviviral NS3 and NS5 proteins. The type 1 cap is formed on (+) strand RNA via the four sequential enzyme activities of RNA triphosphatase, guanylyltransferase, guanine-N7-MTase, and RNA 2'O-MTase. First, triphosphatase activity of the NS3 helicase releases the terminal phosphate from the $5^{\prime}$-triphosphate end of (+) strand RNA. A guanosine monophosphate (GMP) moiety from GTP is transferred to the $5^{\prime}$ end of the now-diphosphorylated RNA through guanylyltransferase activity of the NS5 MTase. The capped RNA is then methylated first at the N7 position of the guanine cap and subsequently at the ribose $2^{\prime}-\mathrm{O}$ position of the first RNA nucleotide. The MTase domain of NS5 carries out both methylations using $S$-adenosyl-L-methionine (AdoMet) as a methyl donor. AdoMet is converted to $S$-adenosyl-L-homosysteine (AdoHcy) during this process. 
The (+) strand progeny RNA is subsequently capped at its $5^{\prime}$ end and methylated to form a type 1 cap (Figure 1B). The cap is shown to be present only on genomic RNA, and not on the dsRNA intermediate (RF form) in WNV-infected cells [38]. The RNA-capping process is likely to occur as the (+) strand RNA is synthesized during the initial stages of RNA synthesis (Figure 1), but little is known about how flavivirus coordinates RNA synthesis and $5^{\prime}$ end RNA capping. The RNA capping and methylation processes require three enzymatic activities. First, the 5'-triphosphate end of (+) RNA is converted into a 5'-diphosphate by the RNA triphosphatase activity of the NS3 helicase. Second, a GMP moiety from GTP is transferred to the $5^{\prime}$-diphosphate RNA by a guanylyltransferase (GTase). The NS5 MTase domain has weak guanylyltransferase activity that transfers a GMP cap from GTP to the $5^{\prime}$ end of (+) sense RNA [23]. Finally, the capped RNA is first methylated at the N7 position of guanine and then at the ribose 2'-OH position of the first nucleotide of the RNA. The MTase domain of NS5 functions as both the N7-MTase and the 2'O-MTase, and transfers a methyl group from the cofactor AdoMet to the substrate capped RNA in both reactions [24,41].

\section{Flaviviral Replication Complex}

Genome replication in flavivirus is carried out by a membrane-bound viral replication complex consisting of viral NS proteins, viral RNA and unidentified host proteins [9]. Membrane fractions prepared from the lysates of flavivirus-infected cells contained virus-specific RNA and proteins, and retained all of the RdRp activity [29]. Flaviviruses alter host cellular membrane structures, presumably to protect the viral RNA and replication proteins from triggering the host immune response and being degraded by cytoplasmic enzymes. Using electron microscopy and tomography, flavivirus (DENV, WNV, and TBEV)-infected cells have been shown to form spherical single-membrane vesicles of 80-100 $\mathrm{nm}$ in diameter via invagination of the ER membrane into the ER lumen $[25,42,43]$ (Figure 2). This contrasts to the related hepatitis $\mathrm{C}$ virus, which shows the double membrane vesicle structures with varied sizes between 150-1000 nm [44,45]. Viral NS proteins NS1, NS2B, NS3, NS4A, NS4B and NS5 along with dsRNA are located in the membrane vesicles, suggesting that these vesicles are the sites of RNA replication $[28,45]$. The vesicles have a pore connecting the interior of the vesicle to the cytoplasm, which is thought to allow exchange of nucleotides and RNA product with the cytoplasm $[25,42]$. In addition, virus particles have been shown to bud out on ER membranes next to the replication vesicles, suggesting that the viral replication and encapsidation of the viral genome/virion assembly are likely coordinated.

Although the exact composition of the replication complex is not known, all flaviviral NS proteins have been shown to be a component of the replication complex. Using immunoprecipitation, yeast two-hybrid, and fluorescence resonance energy transfer (FRET) assays, interactions among NS proteins have been identified [27,46-48] (Figure 2). Membrane proteins NS2B, NS4A, and NS4B are likely involved in membrane alterations and/or anchoring the viral replication complex to the membrane [26]. NS2B interacts with the three other membrane proteins, NS2A, NS4A, and NS4B [47]. NS4A and NS4B have been proposed to interact with NS1 by genetic studies [49,50]. Oligomerization of NS4A, and dimerizations of NS4B and NS1 have also been reported [51,52]. NS3 itself does not have any membrane-association or transmembrane region. However, the active protease function of NS3 (in the $\mathrm{N}$-terminal domain) requires the cofactor NS2B, thus NS3 localizes to the membrane as an NS3-NS2B 
complex [15,47]. NS3 has also been shown to interact with NS4B through its C-terminal helicase domain [53]. NS5 also does not have any membrane-associated region and interacts only with NS3. Thus, NS5 likely accumulates to the membrane via NS3-NS5 interactions. Unidentified host proteins are also involved in viral replication. It has been shown that DENV NS5 protein alone was not able to use a viral dsRNA intermediate (RF form) as a template for RNA synthesis. However, the addition of uninfected cell lysate to the NS5 reaction could restore polymerase activity, suggesting that host proteins are also involved in viral replication [40]. Consequently, an in vitro flaviviral replication system, which can use the viral genome to synthesize the methylated, capped RNA product, is currently unavailable.

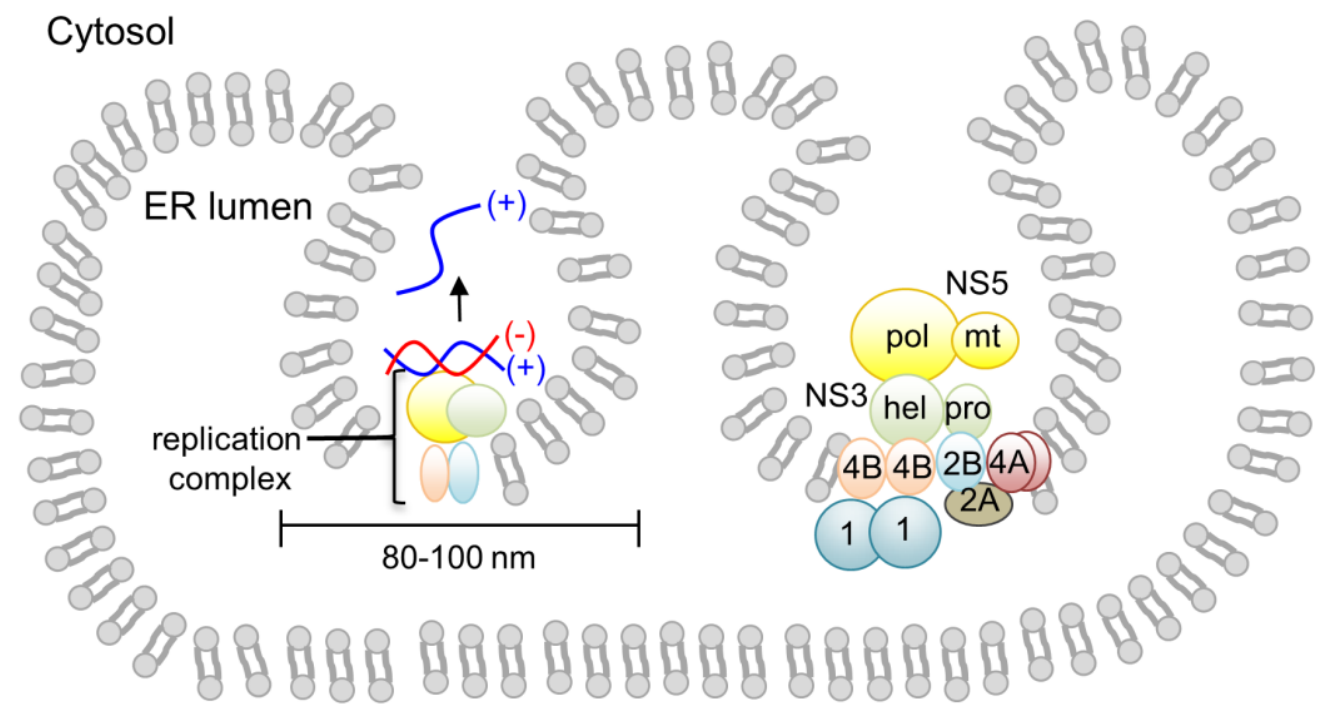

Figure 2. Flaviviral replication complex assembled on the cytoplasmic side of the ER membrane. The viral replication complex is associated with the virus vesicle (single membrane vesicle) formed by invagination of the ER membrane. Interactions between flaviviral NS proteins are indicated schematically. Viral membrane proteins NS2A, NS2B, NS4A, and NS4B form a scaffold for the assembly of NS3 and NS5 proteins. Oligomerization of NS4A and dimerization of NS4B are depicted [51,52]. NS3 interacts with NS2B through its protease domain and with NS4B through its helicase domain. NS5 interacts only with NS3. The NS1 dimer is located in the ER lumen, and associates with NS4A and NS4B.

\section{Inter- and Intramolecular Coordination between NS5 and NS3 during Genome Replication}

At the heart of the flaviviral replication complex are NS3 and NS5, which together account for all enzymatic activities required to amplify the RNA genome and to attach a type 1 cap to its $5^{\prime}$ end (Figure 1). Other viral and host proteins in the viral replication complex would provide additional efficiency and specificity for viral replication. NS5 is involved in RNA synthesis, 5'-RNA cap transfer, and cap methylations. The NS3 helicase domain is involved in dsRNA unwinding and removal of the $\gamma$-phosphate at the 5'-RNA prior to RNA capping. However, how NS3 and NS5 activities are coordinated during viral replication is not known. It is possible that individual activities of the two proteins are modulated by mutual interaction with each other as well as with other proteins and viral RNA [23,54-56]. Interactions between NS3 and NS5 proteins from several flaviviral species have been 
shown using pull-down assays from infected cell extracts, in vivo fluorescent measurements, and yeast two-hybrid studies [46,47,57]. Their respective binding sites map to the C-terminal domain of NS3 (residues 303-618) and the RdRp domain of NS5 (residues 320-368, which also includes a nuclear localization sequence) [58-60].

The physical linkage between the MTase and RdRp domains within NS5 suggests that viral genome replication and 5'-RNA capping may be coordinated between the two domains. Several genetic studies show that mutations in the MTase domain impact RNA replication by the RdRp domain, suggesting that the RdRp and MTase interact during viral genome replication [61-64]. In addition, a full-length DENV type 2 RNA containing an NS5 chimera, in which the MTase from DENV type 4 is fused to the RdRp from DENV type 2, cannot carry out replication although the MTase from DENV type 2 and 4 NS5 share high sequence identity $(\sim 70 \%)$ [65]. This suggests that sequence-specific interactions between the MTase and RdRp domains are necessary for viral replication. Consequently, there has been great interest in carrying out structural and biochemical studies to define whether and/or how coordination between these activities may occur, and how coordination may be exploited to design novel antiviral agents effective against flavivirus infection [66,67]. The individual MTase and RdRp domains from several flaviviral sources have been structurally characterized, but until recently there were no available structures of full-length flavivirus NS5. The crystal structures of full-length NS5 from Japanese encephalitis virus (JEV) and DENV were recently reported, and provided a first glimpse into how the MTase and RdRp domains interact.

\section{Full-Length NS5 Structure and Function}

The recently reported structures of full-length NS5 from JEV and DENV offer details of specific interactions between the MTase and RdRp domains and suggest a structural mechanism by which their activities may be coordinated within the flavivirus replication complex [68,69]. We have recently determined the crystal structure of DENV NS5 as a dimer (in preparation), and will provide an overview of the three structures (Figure 3). Briefly, the MTase domain contains a central core structure characteristic of AdoMet-dependent MTases consisting of a 7 -stranded $\beta$-sheet surrounded by $4 \alpha$-helices. The RdRp domain adopts the shape of a closed right hand and consists of palm, fingers, and thumb subdomains. The inner surfaces of the fingers and thumb subdomains form the entrance to a template-binding channel that leads to the active site in the palm subdomain. The locations of respective active sites in the MTase and the RdRp are indicated in Figure 3. Surprisingly, in both JEV and DENV full-length NS5 the active sites of the MTase and RdRp domains are located on opposite faces and do not interact with each other. The MTase domain sits "behind" the RdRp domain when viewed in its right hand orientation, opposite the dsRNA exit channel and close to the template-binding channel (Figure 3). In all three structures, the individual MTase and RdRp domains are nearly superimposable with one another. The major difference between the JEV and DENV NS5 structures is the relative orientation of the MTase and RdRp domains, primarily due to different conformations of the inter-domain linker (residues 263-272, DENV type 3 numbering). The MTase domains in JEV and DENV NS5 are rotated relative to one another by $\sim 100^{\circ}$. A strictly conserved ${ }^{260} \mathrm{Gly}-\mathrm{Thr}-\mathrm{Arg}^{262}$ (GTR) motif, N-terminal to the inter-domain linker, is proposed to act as a hinge that allows movement of the MTase and RdRp domains relative to one another [68-70]. Accordingly, the relative orientation of the MTase and RdRp 
active sites are quite different in JEV and DENV NS5, and the domain interfaces involve different sets of MTase residues to interact with the same area of the RdRp. In the JEV NS5, the domain interface centers around a hydrophobic core consisting of residues P113, L115, and W121 from the MTase domain, and F467, F351, and P585 from the RdRp. In contrast, the domain interface in DENV NS5 is stabilized mainly by polar and electrostatic interactions involving MTase residues Q63, E252, and D256 to interact with relatively the same area of RdRp (Figure 3). Interestingly, the MTase residues involved in the inter-domain interactions in the JEV NS5 monomer (P113, P115, and W121 in DENV numbering) are present at the dimer interface in our DENV NS5 dimer structure. Thus, the same MTase region mediates intra- and inter-molecular interactions with the RdRp domain in JEV and DENV NS5, respectively, suggesting that NS5 may also function as a dimer (Figure 3). Taken together, comparison of the full-length NS5 structures from JEV and DENV shows that flavivirus NS5 can alter relative MTase and $\mathrm{RdRp}$ domain orientations and its monomer-dimer state by modulating its linker region. This may endow NS5 with the flexibility it needs to carry out multiple functions in the replication complex and interact with other proteins at different steps of viral replication (see below).
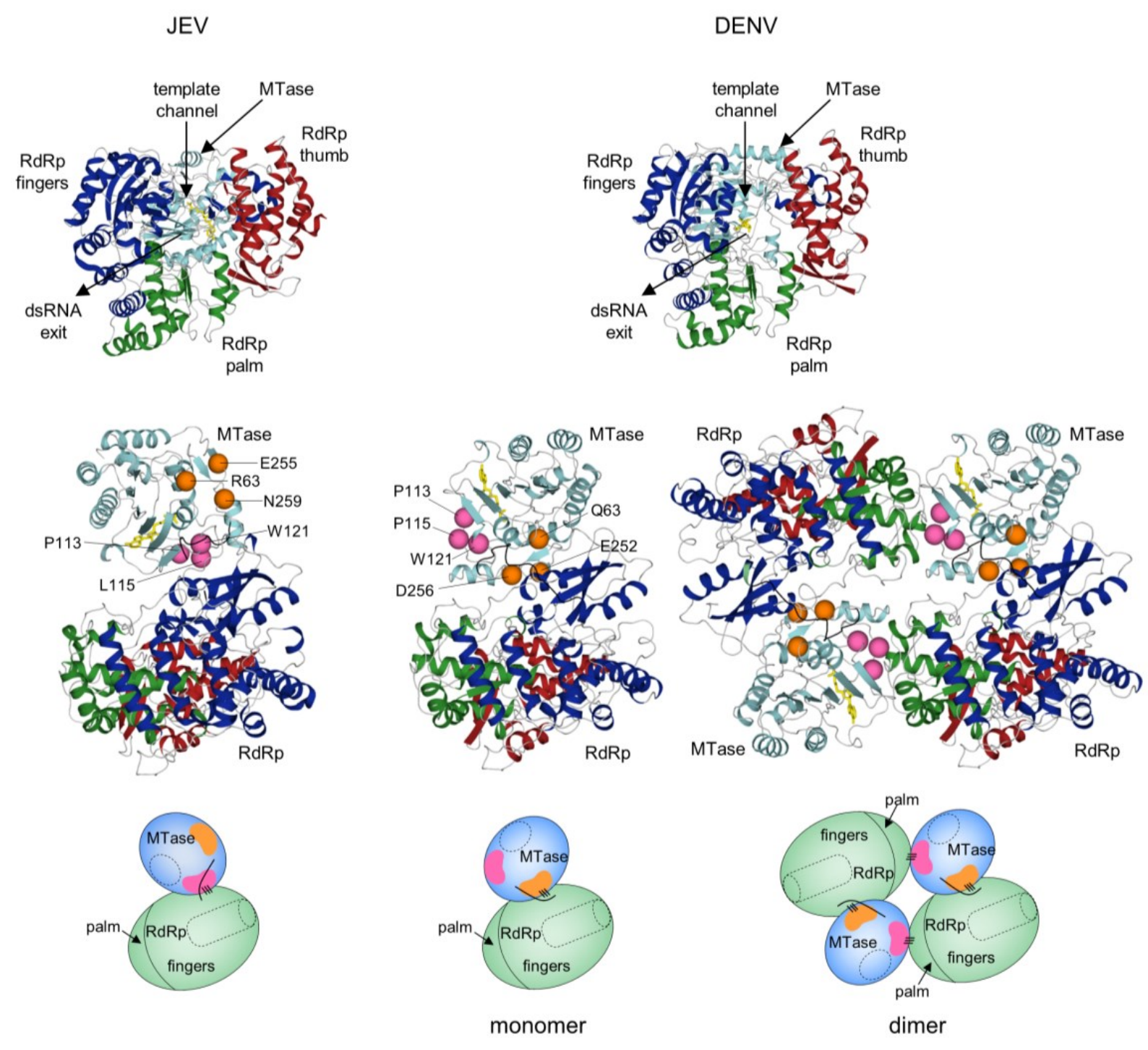

Figure 3. Comparison of full-length NS5 structures from JEV and DENV. Overall fold of JEV and DENV full-length NS5 (Protein Data Bank entries 4K6M and 4VOQ) are shown from 
the canonical right hand view of RdRp (top) and side view (bottom). Side views of both monomer and dimer forms of DENV NS5 are shown. The RdRp domain consists of fingers (green), palm (blue), and thumb (red) subdomains. The MTase domain (cyan) sits opposite the dsRNA exit channel of the RdRp and near the template-binding channel. The methyl donor used during MTase reaction, AdoMet, is shown in yellow. In each structure, the same region of the RdRp contacts the MTase. The MTase residues at the domain interface from JEV and DENV are indicated by pink and orange spheres, respectively. For comparison, corresponding residues are also mapped on the structures. Domain interactions are also indicated in schematics by a series of three lines below the side view. The MTase active site is indicated by dashed ovals, and the RdRp template channel is shown as a dashed tube.

\section{Model of Flaviviral Replication}

The multifunctional flavivirus NS5 carries out several reactions. These include synthesis of $(-)$ strand RNA, synthesis of (+) strand RNA, addition of a guanine cap to the $5^{\prime}$ end of $(+)$ strand RNA, and two methylation reactions to form a type 1 cap structure at the $5^{\prime}$ end of the nascent RNA. Consequently, NS5 interacts with other viral proteins and several different forms of viral RNA, including both single- and double-stranded, (+) and (-) strand, capped and uncapped, and methylated and unmethylated forms of capped RNA. Thus, NS5 likely needs to adopt multiple conformations during different stages of genome replication and processing, as suggested by the conformational variation observed for the structures of full-length NS5 from JEV and DENV. Below, we summarize viral replication steps in terms of coordination of NS3 and NS5 functions.

1. (-) strand RNA synthesis: (-) sense RNA synthesis is carried out by NS5 polymerase using the viral (+) RNA genome as a template. The function of NS3 does not seem to be required for (-) strand RNA synthesis, since NS5 (either the full-length protein or the polymerase domain) alone is capable of synthesizing RNA using viral subgenomic RNA. The (+) sense RNA genome contains cyclization sequences at the $5^{\prime}$ - and $3^{\prime}$-UTR, and the cyclized genome serves as the template for (-) strand RNA synthesis [1-8,71]. NS5 polymerase recognizes a conserved RNA structure called stem loop A (SLA) within the $5^{\prime}$-UTR as a promoter, and initiates (-) strand RNA synthesis at the $3^{\prime}$ end of the genome. The nascent (-) RNA product exists as dsRNA, base-paired with the (+) strand RNA template [29].

2. (+) strand RNA synthesis: The viral replication complex uses the $(-)$ strand RNA in the dsRNA intermediate as the template to synthesize multiple copies of (+) sense RNA. Both NS5 and NS3 activities are required for (+) RNA synthesis (Figure 4). NS3 helicase first unwinds the dsRNA intermediate into (+) and (-) sense RNAs. Following strand separation, the $3^{\prime}$ end of $(-)$ sense RNA will bind the template-binding channel of NS5 RdRp and serve as a template for (+) strand RNA synthesis. Because (-) strand RNA only exists in the dsRNA form, specific RNA interactions, such as those between the cyclization sequences or stem loop structures necessary for (-) strand synthesis, are not required for (+) sense RNA synthesis [29,72]. Upon completion of nascent $(+)$ sense RNA synthesis, a dsRNA product (consisting of the nascent $(+)$ strand and the 
(-) strand template) will be released from the RdRp and recycled for another round of (+) strand RNA synthesis [29,36].

3. 5'-RNA capping and methylation of (+) sense RNA: The (+) sense RNA will be capped and methylated to form a type 1 cap at the $5^{\prime}$ end (Figure 1B). NS3 helicase hydrolyzes the $5^{\prime}$-terminal phosphate of (+) sense RNA and converts it to a diphosphate using its RNA triphosphatase activity. The 5'-diphosphorylated (+) sense RNA then binds the NS5 MTase for capping and methylations. For 5'-RNA capping, NS5 MTase first reacts with GTP to form a covalently linked GMP-enzyme intermediate, and then transfers the GMP moiety to the 5'-diphosphate of the (+) strand RNA [23]. Next, the MTase methylates the N7 position of the guanine cap and the ribose $2^{\prime}-\mathrm{OH}$ position of the first nucleotide. Each methylation reaction requires distinct RNA sequences and lengths, and N7 cap methylation requires the presence of the stem loop A in the $5^{\prime}$-UTR of the viral genome [73]. Since the NS5 MTase carries out three separate reactions using one active site, the $5^{\prime}$ end of (+) RNA needs to dissociate and then re-associate with the MTase at each step [74].

4. Coordination of (+) RNA synthesis and 5'-RNA capping: The 5'-RNA capping and methylation steps are likely coupled with (+) sense RNA synthesis, but during which step of RNA synthesis $5^{\prime}$-RNA capping and methylation occur is not clear. Capping of 5'-RNA could occur on the nascent (+) strand RNA while it is being synthesized by the NS5 RdRp domain (co-transcriptional model in Figure 4A). After a short stretch of $(+)$ sense RNA is synthesized, the $5^{\prime}$ end of the nascent (+) RNA could be dephosphorylated by NS3 helicase, and capped and methylated by NS5 MTase. The 5'-capped (+) sense RNA will then be continuously synthesized until the entire $(-)$ strand is copied. Alternatively, the $5^{\prime}$-RNA capping could occur on the preexisting full-length (+) RNA that is separated from the (-) strand template RNA by NS3 helicase (post-transcriptional model in Figure 4A). Upon unwinding of dsRNA, NS3 helicase hydrolyzes the 5'-terminal phosphate of (+) sense RNA and NS5 MTase subsequently attaches the type 1 cap to the $5^{\prime}$ end. The consequential difference between the two mechanisms would be whether the (+) strand RNA in the dsRNA form is capped. In the co-transcriptional model, all (+) strand RNA, either ssRNA or dsRNA, would be capped and methylated because the nascent RNA is co-transcriptionally capped and methylated. In the post-transcriptional model, only displaced (+) strand RNA, and not the (+) sense RNA in the dsRNA form, would be capped and methylated. Since the cap is shown to be present only on genomic (+) sense RNA, and not on the dsRNA form in WNV-infected cell $[29,38]$, it seems likely that $5^{\prime}$-capping occurs on the fully synthesized (+) sense RNA. In this case, upon completion of a cycle of nascent $(+)$ sense RNA synthesis, a dsRNA product and a capped $(+)$ strand RNA (identical to the viral genome) will be released from the RdRp and MTase domains of NS5 (Figure 4B). 
(A)
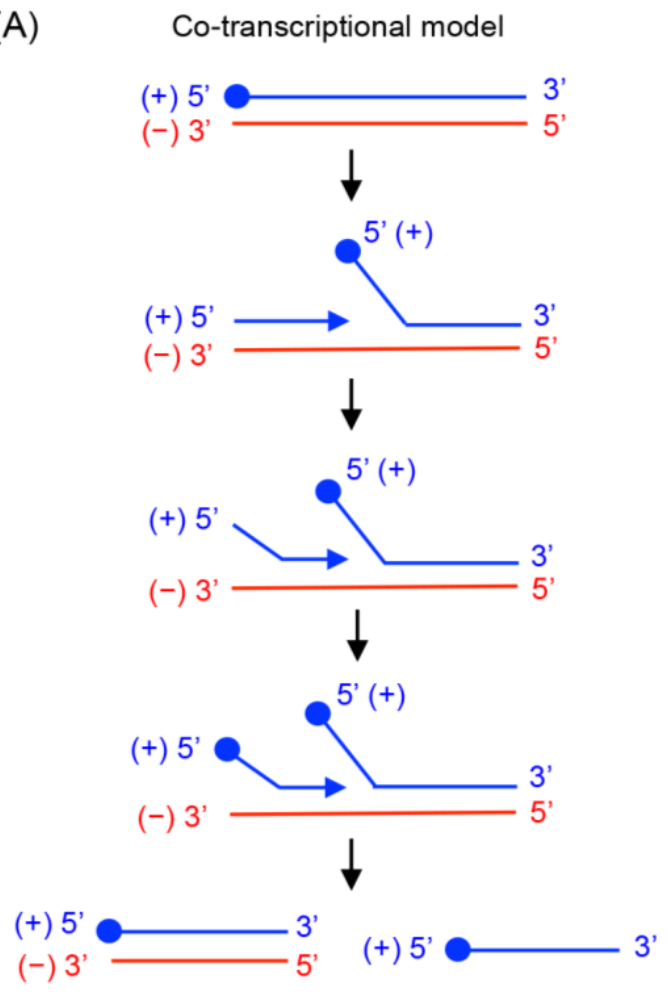

Post-transcriptional model

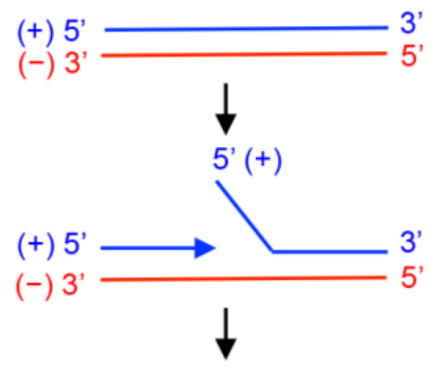

$(+)$
(-) 3 ,

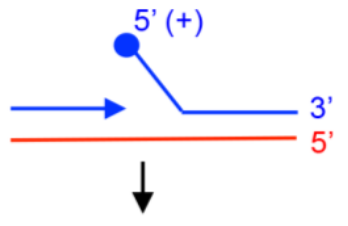

(+) 5 '

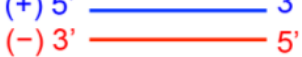

(+) 5 ii.

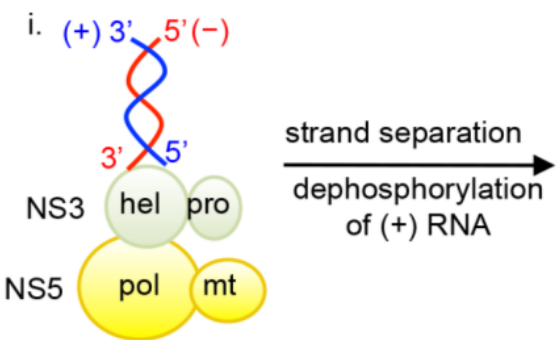

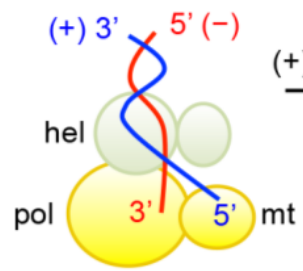

iii. +) RNA synthesis

5 ' capping of (+) RNA

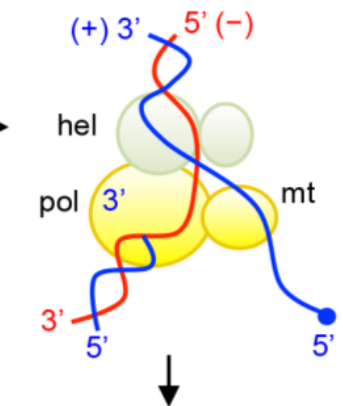

Recycle as template
$(-)$

(+)

dsRNA

(+)

5'-capped RNA

Figure 4. Possible mechanisms of coordination between RNA synthesis and $5^{\prime}$-RNA capping. (A) Two possible mechanisms are proposed for 5'-RNA capping for (+) sense RNA. In a co-transcriptional model, $5^{\prime}$-RNA capping occurs co-transcriptionally while nascent $(+)$ sense RNA is being synthesized from dsRNA replicative form. After a short stretch of (+) sense RNA being synthesized, the $5^{\prime}$ end of the nascent (+) RNA would be dephosphorylated by NS3 helicase, and capped and methylated by NS5 MTase. The cap structure is depicted with a closed circle. The $5^{\prime}$-capped (+) sense RNA would then be continuously synthesized until the entire $(-)$ strand is copied. Upon completion of a cycle, a dsRNA containing a capped (+) strand and a capped (+) RNA are synthesized. In a post-transcriptional model, 5 -RNA capping occurs on the fully synthesized $(+)$ strand RNA. Following strand separation of dsRNA, the (+) sense RNA could be dephoshphorylated by NS3 helicase, and capped and methylated by NS5 MTase. Upon completion of a cycle, a dsRNA and a capped (+) RNA are synthesized. (B) Coordination of RNA synthesis and 5'-RNA capping by flavivirus NS3 and NS5 in the post-transcriptional model. (i) NS3 helicase unwinds the dsRNA intermediate into 
(+) and (-) sense RNA, and hydrolyzes the $5^{\prime}$ end of (+) sense RNA by its $5^{\prime}$-RNA triphosphatase activity. (ii) The $3^{\prime}$ end of the (-) strand RNA will enter the NS5 RdRp template-binding channel, and serve as a template for (+) strand RNA synthesis. The 5'-dephosphorylated (+) RNA enters the NS5 MTase active site for 5'-RNA capping and methylations. (iii) Upon completion of nascent (+) sense RNA synthesis, a dsRNA and a 5 '-capped (+) strand RNA are released from the NS5 RdRp and MTase domains. The dsRNA product, consisting of the $(-)$ strand template and nascent $(+)$ strand, is then recycled for another round of $(+)$ strand RNA synthesis.

\section{Conclusions and Future Perspectives}

The identification and visualization of subcellular membrane structures used by flavivirus as replication factories have provided insight into how flavivirus may orchestrate viral replication and virion assembly in infected cells. Additionally, crystal structures of the full-length NS5 have provided details of intra- and inter-molecular interactions that stabilize different forms of NS5. These forms may interact with RNA and protein components of the replication complex differently and thus serve as a platform to promote different steps during genome replication. Future studies will be geared toward understanding how these membrane vesicles are related to the assembly and function of the viral replication complex at the molecular level. In particular, how flaviviral and host proteins establish such elaborate membrane vesicles for replication, how flaviviral NS proteins are assembled in the membrane-bound viral replication complex, and how the viral replication complex carries out individual steps of RNA replication are of great interest.

\section{Acknowledgments}

This work was supported by NIH Research Grants AI087856 (to K.H.C. and R.P) and AI105985 (to K.H.C.).

\section{Author Contributions}

V.J.K., R.P. and K.H.C. wrote the paper.

\section{Conflicts of Interest}

The authors declare no conflict of interest.

\section{References}

1. Lodeiro, M.F.; Filomatori, C.V.; Gamarnik, A.V. Structural and functional studies of the promoter element for dengue virus RNA replication. J. Virol. 2009, 83, 993-1008. [CrossRef] [PubMed]

2. Filomatori, C.V.; Lodeiro, M.F.; Alvarez, D.E.; Samsa, M.M.; Pietrasanta, L.; Gamarnik, A.V. A 5' RNA element promotes dengue virus RNA synthesis on a circular genome. Genes Dev. 2006, 20, 2238-2249. [CrossRef] [PubMed] 
3. Ackermann, M.; Padmanabhan, R. De novo synthesis of RNA by the dengue virus RNA-dependent RNA polymerase exhibits temperature dependence at the initiation but not elongation phase. J. Biol. Chem. 2001, 276, 39926-39937. [CrossRef] [PubMed]

4. You, S.; Falgout, B.; Markoff, L.; Padmanabhan, R. In vitro RNA synthesis from exogenous dengue viral rna templates requires long range interactions between $5^{\prime}$ - and $3^{\prime}$-terminal regions that influence RNA structure. J. Biol. Chem. 2001, 276, 15581-15591. [CrossRef] [PubMed]

5. Hahn, C.S.; Hahn, Y.S.; Rice, C.M.; Lee, E.; Dalgarno, L.; Strauss, E.G.; Strauss, J.H. Conserved elements in the $3^{\prime}$ untranslated region of flavivirus RNAs and potential cyclization sequences. J. Mol. Biol. 1987, 198, 33-41. [CrossRef]

6. Khromykh, A.A.; Meka, H.; Guyatt, K.J.; Westaway, E.G. Essential role of cyclization sequences in flavivirus RNA replication. J. Virol. 2001, 75, 6719-6728. [CrossRef] [PubMed]

7. Corver, J.; Lenches, E.; Smith, K.; Robison, R.A.; Sando, T.; Strauss, E.G.; Strauss, J.H. Fine mapping of a cis-acting sequence element in yellow fever virus RNA that is required for RNA replication and cyclization. J. Virol. 2003, 77, 2265-2270. [CrossRef] [PubMed]

8. Lo, M.K.; Tilgner, M.; Bernard, K.A.; Shi, P.Y. Functional analysis of mosquito-borne flavivirus conserved sequence elements within $3^{\prime}$ untranslated region of West Nile virus by use of a reporting replicon that differentiates between viral translation and RNA replication. J. Virol. 2003, 77, 10004-10014. [CrossRef] [PubMed]

9. Lindenbach, B.D.; Thiel, H.J.; Rice, C.M. Flaviviridae: The Viruses and Their Replication; Lippincott-Raven Publishers: Philadelphia, PA, USA, 2007; Volume 1, pp. 1101-1152.

10. Falgout, B.; Pethel, M.; Zhang, Y.M.; Lai, C.J. Both nonstructural proteins NS2B and NS3 are required for the proteolytic processing of dengue virus nonstructural proteins. J. Virol. 1991, 65, 2467-2475. [PubMed]

11. Yusof, R.; Clum, S.; Wetzel, M.; Murthy, H.M.; Padmanabhan, R. Purified NS2B/NS3 serine protease of dengue virus type 2 exhibits cofactor NS2B dependence for cleavage of substrates with dibasic amino acids in vitro. J. Biol. Chem. 2000, 275, 9963-9969. [CrossRef] [PubMed]

12. Chambers, T.J.; Weir, R.C.; Grakoui, A.; McCourt, D.W.; Bazan, J.F.; Fletterick, R.J.; Rice, C.M. Evidence that the N-terminal domain of nonstructural protein NS3 from yellow fever virus is a serine protease responsible for site-specific cleavages in the viral polyprotein. Proc. Natl. Acad. Sci. USA 1990, 87, 8898-8902. [CrossRef] [PubMed]

13. Jan, L.R.; Yang, C.S.; Trent, D.W.; Falgout, B.; Lai, C.J. Processing of japanese encephalitis virus non-structural proteins: NS2B-NS3 complex and heterologous proteases. J. Gen. Virol. 1995, 76 (Pt 3), 573-580. [CrossRef] [PubMed]

14. Clum, S.; Ebner, K.E.; Padmanabhan, R. Cotranslational membrane insertion of the serine proteinase precursor NS2B-NS3(pro) of dengue virus type 2 is required for efficient in vitro processing and is mediated through the hydrophobic regions of NS2B. J. Biol. Chem. 1997, 272, 30715-30723. [CrossRef] [PubMed]

15. Li, H.; Clum, S.; You, S.; Ebner, K.E.; Padmanabhan, R. The serine protease and RNA-stimulated nucleoside triphosphatase and RNA helicase functional domains of dengue virus type 2 NS3 converge within a region of 20 amino acids. J. Virol. 1999, 73, 3108-3116. [PubMed] 
16. Matusan, A.E.; Pryor, M.J.; Davidson, A.D.; Wright, P.J. Mutagenesis of the dengue virus type 2 NS3 protein within and outside helicase motifs: Effects on enzyme activity and virus replication. J. Virol. 2001, 75, 9633-9643. [CrossRef] [PubMed]

17. Bartelma, G.; Padmanabhan, R. Expression, purification, and characterization of the RNA 5 -triphosphatase activity of dengue virus type 2 nonstructural protein 3. Virology 2002, 299, 122-132. [CrossRef] [PubMed]

18. Benarroch, D.; Selisko, B.; Locatelli, G.A.; Maga, G.; Romette, J.L.; Canard, B. The RNA helicase, nucleotide 5'-triphosphatase, and RNA 5'-triphosphatase activities of dengue virus protein NS3 are $\mathrm{Mg}^{2+}$-dependent and require a functional walker $\mathrm{B}$ motif in the helicase catalytic core. Virology 2004, 328, 208-218. [CrossRef] [PubMed]

19. Wengler, G.; Wengler, G. The NS 3 nonstructural protein of flaviviruses contains an RNA triphosphatase activity. Virology 1993, 197, 265-273. [CrossRef] [PubMed]

20. Xu, T.; Sampath, A.; Chao, A.; Wen, D.; Nanao, M.; Chene, P.; Vasudevan, S.G.; Lescar, J. Structure of the dengue virus helicase/nucleoside triphosphatase catalytic domain at a resolution of 2.4 a. J. Virol. 2005, 79, 10278-10288. [CrossRef] [PubMed]

21. Wang, C.C.; Huang, Z.S.; Chiang, P.L.; Chen, C.T.; Wu, H.N. Analysis of the nucleoside triphosphatase, RNA triphosphatase, and unwinding activities of the helicase domain of dengue virus NS3 protein. FEBS Lett. 2009, 583, 691-696. [CrossRef] [PubMed]

22. Chu, P.W.; Westaway, E.G. Replication strategy of kunjin virus: Evidence for recycling role of replicative form RNA as template in semiconservative and asymmetric replication. Virology 1985, 140, 68-79. [CrossRef]

23. Issur, M.; Geiss, B.J.; Bougie, I.; Picard-Jean, F.; Despins, S.; Mayette, J.; Hobdey, S.E.; Bisaillon, M. The flavivirus NS5 protein is a true RNA guanylyltransferase that catalyzes a two-step reaction to form the RNA cap structure. RNA 2009, 15, 2340-2350. [CrossRef] [PubMed]

24. Egloff, M.P.; Benarroch, D.; Selisko, B.; Romette, J.L.; Canard, B. An RNA cap (nucleoside-2'-o-)-methyltransferase in the flavivirus RNA polymerase NS5: Crystal structure and functional characterization. EMBO J. 2002, 21, 2757-2768. [CrossRef] [PubMed]

25. Welsch, S.; Miller, S.; Romero-Brey, I.; Merz, A.; Bleck, C.K.; Walther, P.; Fuller, S.D.; Antony, C.; Krijnse-Locker, J.; Bartenschlager, R. Composition and three-dimensional architecture of the dengue virus replication and assembly sites. Cell. Host Microbe 2009, 5, 365-375. [CrossRef] [PubMed]

26. Miller, S.; Kastner, S.; Krijnse-Locker, J.; Buhler, S.; Bartenschlager, R. The non-structural protein $4 \mathrm{~A}$ of dengue virus is an integral membrane protein inducing membrane alterations in a 2k-regulated manner. J. Biol. Chem. 2007, 282, 8873-8882. [CrossRef] [PubMed]

27. Westaway, E.G.; Mackenzie, J.M.; Kenney, M.T.; Jones, M.K.; Khromykh, A.A. Ultrastructure of kunjin virus-infected cells: Colocalization of NS1 and NS3 with double-stranded RNA, and of NS2b with NS3, in virus-induced membrane structures. J. Virol. 1997, 71, 6650-6661. [PubMed]

28. Mackenzie, J.M.; Khromykh, A.A.; Jones, M.K.; Westaway, E.G. Subcellular localization and some biochemical properties of the flavivirus kunjin nonstructural proteins NS2A and NS4A. Virology 1998, 245, 203-215. [CrossRef] [PubMed] 
29. Westaway, E.G.; Mackenzie, J.M.; Khromykh, A.A. Kunjin RNA replication and applications of kunjin replicons. Adv. Virus Res. 2003, 59, 99-140. [PubMed]

30. Youn, S.; Ambrose, R.L.; Mackenzie, J.M.; Diamond, M.S. Non-structural protein-1 is required for West Nile virus replication complex formation and viral RNA synthesis. Virol. J. 2013, 10, e339. [CrossRef] [PubMed]

31. Mackenzie, J.M.; Jones, M.K.; Young, P.R. Immunolocalization of the dengue virus nonstructural glycoprotein NS1 suggests a role in viral RNA replication. Virology 1996, 220, 232-240. [CrossRef] [PubMed]

32. Khromykh, A.A.; Sedlak, P.L.; Guyatt, K.J.; Hall, R.A.; Westaway, E.G. Efficient trans-complementation of the flavivirus kunjin NS5 protein but not of the NS1 protein requires its coexpression with other components of the viral replicase. J. Virol. 1999, 73, 10272-10280. [PubMed]

33. Lindenbach, B.D.; Rice, C.M. Trans-complementation of yellow fever virus NS1 reveals a role in early RNA replication. J. Virol. 1997, 71, 9608-9617. [PubMed]

34. Flamand, M.; Megret, F.; Mathieu, M.; Lepault, J.; Rey, F.A.; Deubel, V. Dengue virus type 1 nonstructural glycoprotein NS1 is secreted from mammalian cells as a soluble hexamer in a glycosylation-dependent fashion. J. Virol. 1999, 73, 6104-6110. [PubMed]

35. Winkler, G.; Maxwell, S.E.; Ruemmler, C.; Stollar, V. Newly synthesized dengue-2 virus nonstructural protein NS1 is a soluble protein but becomes partially hydrophobic and membrane-associated after dimerization. Virology 1989, 171, 302-305. [CrossRef]

36. Roby, J.A.; Funk, A.; Khromykh, A.A. Flavivirus replication and assembly. In Molecular Virology and Control of Flaviviruses; Shi, P.Y., Ed.; Caister Academic Press: Norfolk, UK, 2012.

37. Brinton, M.A. Replication cycle and molecular biology of the West Nile virus. Viruses 2014, 6, 13-53. [CrossRef] [PubMed]

38. Wengler, G.; Wengler, G.; Gross, H.J. Studies on virus-specific nucleic acids synthesized in vertebrate and mosquito cells infected with flaviviruses. Virology 1978, 89, 423-437. [CrossRef]

39. Cleaves, G.R.; Ryan, T.E.; Schlesinger, R.W. Identification and characterization of type 2 dengue virus replicative intermediate and replicative form RNAs. Virology 1981, 111, 73-83. [CrossRef]

40. Raviprakash, K.; Sinha, M.; Hayes, C.G.; Porter, K.R. Conversion of dengue virus replicative form RNA (RF) to replicative intermediate (RI) by nonstructural proteins NS-5 and NS-3. Am. J. Trop. Med. Hyg. 1998, 58, 90-95. [PubMed]

41. Ray, D.; Shah, A.; Tilgner, M.; Guo, Y.; Zhao, Y.; Dong, H.; Deas, T.S.; Zhou, Y.; Li, H.; Shi, P.Y. West Nile virus $5^{\prime}$-cap structure is formed by sequential guanine $\mathrm{N}-7$ and ribose $2^{\prime}$-O methylations by nonstructural protein 5. J. Virol. 2006, 80, 8362-8370. [CrossRef] [PubMed]

42. Miorin, L.; Romero-Brey, I.; Maiuri, P.; Hoppe, S.; Krijnse-Locker, J.; Bartenschlager, R.; Marcello, A. Three-dimensional architecture of tick-borne encephalitis virus replication sites and trafficking of the replicated RNA. J. Virol. 2013, 87, 6469-6481. [CrossRef] [PubMed]

43. Gillespie, L.K.; Hoenen, A.; Morgan, G.; Mackenzie, J.M. The endoplasmic reticulum provides the membrane platform for biogenesis of the flavivirus replication complex. J. Virol. 2010, 84, 10438-10447. [CrossRef] [PubMed] 
44. Romero-Brey, I.; Merz, A.; Chiramel, A.; Lee, J.Y.; Chlanda, P.; Haselman, U.; Santarella-Mellwig, R.; Habermann, A.; Hoppe, S.; Kallis, S.; et al. Three-dimensional architecture and biogenesis of membrane structures associated with hepatitis C virus replication. PLoS Pathog. 2012, 8, e1003056. [CrossRef] [PubMed]

45. Harak, C.; Lohmann, V. Ultrastructure of the replication sites of positive-strand RNA viruses. Virology 2015, 479-480. [CrossRef] [PubMed]

46. Kapoor, M.; Zhang, L.; Ramachandra, M.; Kusukawa, J.; Ebner, K.E.; Padmanabhan, R. Association between NS3 and NS5 proteins of dengue virus type 2 in the putative RNA replicase is linked to differential phosphorylation of NS5. J. Biol. Chem. 1995, 270, 19100-19106. [PubMed]

47. Yu, L.; Takeda, K.; Markoff, L. Protein-protein interactions among West Nile non-structural proteins and transmembrane complex formation in mammalian cells. Virology 2013, 446, 365-377. [CrossRef] [PubMed]

48. Chen, C.J.; Kuo, M.D.; Chien, L.J.; Hsu, S.L.; Wang, Y.M.; Lin, J.H. RNA-protein interactions: Involvement of NS3, NS5, and 3' noncoding regions of japanese encephalitis virus genomic RNA. J. Virol. 1997, 71, 3466-3473. [PubMed]

49. Youn, S.; Li, T.; McCune, B.T.; Edeling, M.A.; Fremont, D.H.; Cristea, I.M.; Diamond, M.S. Evidence for a genetic and physical interaction between nonstructural proteins NS1 and NS4B that modulates replication of West Nile virus. J. Virol. 2012, 86, 7360-7371. [CrossRef] [PubMed]

50. Lindenbach, B.D.; Rice, C.M. Genetic interaction of flavivirus nonstructural proteins NS1 and NS4A as a determinant of replicase function. J. Virol. 1999, 73, 4611-4621. [PubMed]

51. Stern, O.; Hung, Y.F.; Valdau, O.; Yaffe, Y.; Harris, E.; Hoffmann, S.; Willbold, D.; Sklan, E.H. An N-terminal amphipathic helix in dengue virus nonstructural protein 4A mediates oligomerization and is essential for replication. J. Virol. 2013, 87, 4080-4085. [CrossRef] [PubMed]

52. Zou, J.; Xie, X.; Lee le, T.; Chandrasekaran, R.; Reynaud, A.; Yap, L.; Wang, Q.Y.; Dong, H.; Kang, C.; Yuan, Z.; et al. Dimerization of flavivirus NS4B protein. J. Virol. 2014, 88, 3379-3391. [CrossRef] [PubMed]

53. Umareddy, I.; Chao, A.; Sampath, A.; Gu, F.; Vasudevan, S.G. Dengue virus NS4B interacts with NS3 and dissociates it from single-stranded RNA. J. Gen. Virol. 2006, 87, 2605-2614. [CrossRef] [PubMed]

54. Cui, T.; Sugrue, R.J.; Xu, Q.; Lee, A.K.; Chan, Y.C.; Fu, J. Recombinant dengue virus type 1 NS3 protein exhibits specific viral RNA binding and NTPase activity regulated by the NS5 protein. Virology 1998, 246, 409-417. [CrossRef] [PubMed]

55. Yon, C.; Teramoto, T.; Mueller, N.; Phelan, J.; Ganesh, V.K.; Murthy, K.H.; Padmanabhan, R. Modulation of the nucleoside triphosphatase/RNA helicase and 5'-RNA triphosphatase activities of dengue virus type 2 nonstructural protein 3 (NS3) by interaction with NS5, the RNA-dependent RNA polymerase. J. Biol. Chem. 2005, 280, 27412-27419. [CrossRef] [PubMed]

56. Liu, W.J.; Sedlak, P.L.; Kondratieva, N.; Khromykh, A.A. Complementation analysis of the flavivirus kunjin NS3 and NS5 proteins defines the minimal regions essential for formation of a replication complex and shows a requirement of NS3 in cis for virus assembly. J. Virol. 2002, 76, 10766-10775. [CrossRef] [PubMed] 
57. Johansson, M.; Brooks, A.J.; Jans, D.A.; Vasudevan, S.G. A small region of the dengue virus-encoded RNA-dependent RNA polymerase, NS5, confers interaction with both the nuclear transport receptor importin-beta and the viral helicase, NS3. J. Gen. Virol. 2001, 82, 735-745. [PubMed]

58. Tay, M.Y.; Saw, W.G.; Zhao, Y.; Chan, K.W.; Singh, D.; Chong, Y.; Forwood, J.K.; Ooi, E.E.; Gruber, G.; Lescar, J.; et al. The C-terminal 50 amino acid residues of dengue NS3 protein are important for NS3-NS5 interaction and viral replication. J. Biol. Chem. 2015, 290, 2379-2394. [CrossRef] [PubMed]

59. Moreland, N.J.; Tay, M.Y.; Lim, E.; Rathore, A.P.; Lim, A.P.; Hanson, B.J.; Vasudevan, S.G. Monoclonal antibodies against dengue NS2B and NS3 proteins for the study of protein interactions in the flaviviral replication complex. J. Virol. Methods 2012, 179, 97-103. [CrossRef] [PubMed]

60. Zou, G.; Chen, Y.L.; Dong, H.; Lim, C.C.; Yap, L.J.; Yau, Y.H.; Shochat, S.G.; Lescar, J.; Shi, P.Y. Functional analysis of two cavities in flavivirus NS5 polymerase. J. Biol. Chem. 2011, 286, 14362-14372. [CrossRef] [PubMed]

61. Tan, C.S.; Hobson-Peters, J.M.; Stoermer, M.J.; Fairlie, D.P.; Khromykh, A.A.; Hall, R.A. An interaction between the methyltransferase and RNA dependent RNA polymerase domains of the West Nile virus NS5 protein. J. Gen. Virol. 2013, 94, 1961-1971. [CrossRef] [PubMed]

62. Zhang, B.; Dong, H.; Zhou, Y.; Shi, P.Y. Genetic interactions among the West Nile virus methyltransferase, the RNA-dependent RNA polymerase, and the 5' stem-loop of genomic RNA. J. Virol. 2008, 82, 7047-7058. [CrossRef] [PubMed]

63. Malet, H.; Egloff, M.P.; Selisko, B.; Butcher, R.E.; Wright, P.J.; Roberts, M.; Gruez, A.; Sulzenbacher, G.; Vonrhein, C.; Bricogne, G.; et al. Crystal structure of the RNA polymerase domain of the West Nile virus non-structural protein 5. J. Biol. Chem. 2007, 282, 10678-10689. [CrossRef] [PubMed]

64. Potisopon, S.; Priet, S.; Collet, A.; Decroly, E.; Canard, B.; Selisko, B. The methyltransferase domain of dengue virus protein NS5 ensures efficient RNA synthesis initiation and elongation by the polymerase domain. Nucleic Acids Res. 2014, 42, 11642-11656. [CrossRef] [PubMed]

65. Teramoto, T.; Boonyasuppayakorn, S.; Handley, M.; Choi, K.H.; Padmanabhan, R. Substitution of NS5 N-terminal domain of dengue virus type 2 RNA with type 4 domain caused impaired replication and emergence of adaptive mutants with enhanced fitness. J. Biol. Chem. 2014, 289, 22385-22400. [CrossRef] [PubMed]

66. Bussetta, C.; Choi, K.H. Dengue virus nonstructural protein 5 adopts multiple conformations in solution. Biochemistry 2012, 51, 5921-5931. [CrossRef] [PubMed]

67. Takahashi, H.; Takahashi, C.; Moreland, N.J.; Chang, Y.T.; Sawasaki, T.; Ryo, A.; Vasudevan, S.G.; Suzuki, Y.; Yamamoto, N. Establishment of a robust dengue virus NS3-NS5 binding assay for identification of protein-protein interaction inhibitors. Antivir. Res. 2012, 96, 305-314. [CrossRef] [PubMed]

68. Lu, G.; Gong, P. Crystal structure of the full-length japanese encephalitis virus NS5 reveals a conserved methyltransferase-polymerase interface. PLoS Pathog. 2013, 9, e1003549. [CrossRef] [PubMed] 
69. Zhao, Y.; Soh, T.S.; Zheng, J.; Chan, K.W.; Phoo, W.W.; Lee, C.C.; Tay, M.Y.; Swaminathan, K.; Cornvik, T.C.; Lim, S.P.; et al. A crystal structure of the dengue virus NS5 protein reveals a novel inter-domain interface essential for protein flexibility and virus replication. PLoS Pathog. 2015, 11, e1004682. [CrossRef] [PubMed]

70. Li, X.D.; Shan, C.; Deng, C.L.; Ye, H.Q.; Shi, P.Y.; Yuan, Z.M.; Gong, P.; Zhang, B. The interface between methyltransferase and polymerase of NS5 is essential for flavivirus replication. PLoS Negl. Trop. Dis. 2014, 8, e2891. [CrossRef] [PubMed]

71. You, S.; Padmanabhan, R. A novel in vitro replication system for dengue virus. Initiation of RNA synthesis at the $3^{\prime}$-end of exogenous viral RNA templates requires $5^{\prime}$ - and $3^{\prime}$-terminal complementary sequence motifs of the viral RNA. J. Biol. Chem. 1999, 274, 33714-33722. [CrossRef] [PubMed]

72. Nomaguchi, M.; Teramoto, T.; Yu, L.; Markoff, L.; Padmanabhan, R. Requirements for West Nile virus (-)- and (+)-strand subgenomic RNA synthesis in vitro by the viral RNA-dependent RNA polymerase expressed in escherichia coli. J. Biol. Chem. 2004, 279, 12141-12151. [CrossRef] [PubMed]

73. Dong, H.; Ray, D.; Ren, S.; Zhang, B.; Puig-Basagoiti, F.; Takagi, Y.; Ho, C.K.; Li, H.; Shi, P.Y. Distinct RNA elements confer specificity to flavivirus RNA cap methylation events. J. Virol. 2007, 81, 4412-4421. [CrossRef] [PubMed]

74. Dong, H.; Ren, S.; Zhang, B.; Zhou, Y.; Puig-Basagoiti, F.; Li, H.; Shi, P.Y. West Nile virus methyltransferase catalyzes two methylations of the viral RNA cap through a substrate-repositioning mechanism. J. Virol. 2008, 82, 4295-4307. [CrossRef] [PubMed]

(C) 2015 by the authors; licensee MDPI, Basel, Switzerland. This article is an open access article distributed under the terms and conditions of the Creative Commons Attribution license (http://creativecommons.org/licenses/by/4.0/). 